\title{
The Industry-University-Research Cooperation Innovation of Colleges
}

\author{
Andong Wang ${ }^{*}$, Caifeng Chen ${ }^{b}$,Juan yang ${ }^{c}$, Xiaonong Cheng ${ }^{d}$, \\ Honghong Shao ${ }^{e}$, Zhizhong Yuan ${ }^{\dagger}$ \\ School of Materials Science and Engineering, Jiangsu University, Zhenjiang, China \\ awadujs@163.com, ${ }^{b}$ chenjsust@163.com, ${ }^{c}$ yangjuan6347@ujs.edu.cn, ${ }^{d}$ xncheng@ujs.edu.cn
}

\begin{abstract}
Keywords: College; Collaborative innovation; Industry-University-Research; Enterprise.
Abstract. It's a hotspot for current colleges to actively continue and promote coordination innovation with local enterprise. In order to develop the industry-university-institute cooperation in colleges, the experience of innovation cooperation and development was summarized in the paper. Based on presenting the concept of the collaborative innovation, problems existed in the industry-university-research cooperation of colleges were studied, and the methods for resolving these problems were also suggested.
\end{abstract}

\section{Introduction}

Economist Joseph Schumpeter has pointed out that innovation is a new combination of factors of production and conditions to introduce production systems in his book named "Theory of Economic Development". The innovation contains the introduction of a new product and a new productional method, opening up a new market, obtaining new supply sources of raw material or semi-finished products. This process has been evolved from monomer innovation to collaborative innovation gradually with the economic globalization and a time of knowledge and economy that rapid development of science and technology[1].

The industry-university-research cooperation innovation is based on that cooperating parties share resources or complementary advantages. Cooperating parties participate, share results and risks and reach contract arrangement of different works to complete a technological innovation together. Its main form of $R \& D$ cooperation is that companies need technology and universities or research institutions provide technology.

\section{Promoting the Concept of Industry-University-Research Cooperation Innovation}

The words, such as "Synergy, Collaboration, Cooperation, Coordination", mean working together and cooperating with each other. In 1971, Hermann Haken, a German scholar, first proposed the concept of synergy and pointed out that the synergy effect of $1+1>2$ is produced by the coordinated and cooperative synchronization of subsystems. Peter Gro, researcher at the Massachusetts Institute of Technology's Sloan Center, first defined "cooperation innovation". Namely, the network groups composed of self motivated person come to an idea and exchange ideas, information and working conditions by internet to achieve common goals. The concept of Industry-University-Research cooperation innovation reflects the idea of system. Enterprises and universities, research institutions and intermediary organizations obtain multiply benefits by the interaction between the elements of the formation of innovative effort.

Since 2000, countries all over the world have carried out the research of Industry-University-Research cooperation innovation. Scholars have done a lot of international comparisons analyzed the mode of Industry-University-Research cooperation[2,3]. They think that systematic research on the development between enterprises and universities improves the resource utilization and Industry-University-Research cooperation is an important factor in product innovation[4]. Of course, the operation of research cooperation is also inseparable from the system of government guarantees. Governments introduced various policies to ensure that the Industry-University-Research cooperation can be undertaken smoothly[5]. As in the risk mechanism, 
the Japanese government developed the law of industrial revitalization and strengthening the industrial technology to encourage teachers transforming their research results. In the funding and equipment field, the South Korean government pays $50 \%$ of the development costs, and the transferee pay the remaining 50\%. India government emphasized the personnel training and technology transfer in the Industry-University-Research cooperation. Such as enterprises actively fund the university and help them establish a training system, and participate in the design and explain of courses.

At present, China scholars widely recognize that the promotion of national ability of independent innovation is not a simple sum of various innovative companies, universities and research institutions. It needs coordination and integration of various complementary elements. The promotion and realization of the Industry-University-Research cooperation innovation will make the universities and enterprises obtain a win-win situation from the cooperation. Colleges and universities will obtain the economic support of the enterprises, explore new areas of research, and improve the practicality of research to get more academic results. Enterprises will also receive technical support, enter the field of new technologies and develop new products.

\section{Problems Existing in the Innovation Cooperation of Colleges}

Colleges and universities are the principal place of personnel training, scientific and technological innovation can contribute to the local economy directly. At the same time, cooperation innovation can also promote the connotation development of college education.

It is inevitable for university to innovate cooperatively because of its relationship. However, some problems existed in the Industry-University-Research cooperation of colleges which cannot be ignored now.

Limitations of Universities Scientific Research. Different research areas of universities can not always communicate and cooperate. Most research activities exist in the form of individual or small-scale. Large-level and multidisciplinary scientific and technological innovation is rare. Those problems limit the integration of innovation resources. In addition, the evaluation of universities for talents pay more attention to research projects, published papers and awards. It is lack of follow-up evaluation and promotion of the market value of scientific research. At the same time, a little of scientific research don't meet the socio-economic development. Most companies prefer to seek the research results putting into production quickly and creating effective practical technology.

The Ownership of Intellectual Property Rights. Ownership of intellectual property caused in the process of cooperation is particularly prominent. This dispute not only makes the researchers would not like to take part in cooperation innovation, but also the operation of enterprises will also increase the risk .

The Allocation of Risk and Benefits. At present, the cooperative enterprises desire small investment, short and quick-impact projects. They are unwilling to bear the high risk in the process of combining Industry-University-Research. The achievements in universities scientific research have low commercialization, less practical and uncertain market. This limits the willingness that companies want to cooperate with universities. With the gradual deepening of the cooperation project, when the achievements in scientific research can be translated into economic benefits, the distribution of benefits issues may easy to produce disagreement. This is caused by initial assessment and agreement, or they have no adequate communication.

The Service Platform Needs to Be Strengthened. No scientific and technical services, information delivery is too slow, institutions are not perfect, and so on. These problems lead to achievements in scientific research can not be timely transformed and promoted, and the scientific and technological achievements that the enterprises want can not find a suitable provider. Therefore, it is primary to carry out ideas of Industry-University-Research cooperation innovation and universities or government to provide a comprehensive, efficient, and a platform that can supervise both sides.

The Training of Graduate and Undergraduate Students. Graduate and undergraduate students are the main force in scientific research and they are the bridge that carrying out local 
Industry-University-Research cooperation innovation. Current graduate education in china is divided into academic and professional training mode, but there is no significant difference between the two modes in the actual training process at present. In the process of professional training, many colleges and universities do not strictly required graduate students having a cooperative research experience. High grade undergraduate students are lack of more practice, which lead to the cultivation of students and the development of scientific research can not be very good to meet the needs of enterprises.

\section{How to Achieve Industry-University-Research Cooperation Innovation}

Universities Should Establish the Idea of Service and Lead. "Scientific research creates value, value feedback scientific research". Higher education should satisfy the need of society, and actively participate in and lead the development of the society. In the collaborative innovation of Industry-University-Research, college should train leaders, integrate talents, science and education, and innovation resources. It should also speed up the scientific and technological achievements' transformation and industrialization enhance the ability of social service. The universities should use the way of collaborative innovation to distribute the higher education resources, and become the core force at leading regional economic and social development. And in students' employment, college or universities should actively promote innovative graduates employment to enhance the level of collaborative innovation.

Perfect Relevant Laws and Regulations. Effective value assessment and evaluation system of scientific and technological achievements should be established and perfected. Relevant laws and regulations needs to be perfected, responsibilities and obligations also need to be cleared. Various preferential policies which promote cooperation should be formulated, and relevant government departments are suggested to effectively play the role of supervision and promote. On the basis of respect and protection of intellectual property rights, it is rightful to ensure reasonable interests of all parties concerned, and promote smooth cooperation. In addition, reasonable Industry-University-Interests distribution mechanism should be mutual reciprocity and benefit, also properly placed. Parties concerned should be divided according to their investment ratio. It is further perfect that benefit allocation by means of negotiations.

Optimize the Internal Management of College and Talent Incentive System. To deepen the Industry-University-Research cooperation innovation, colleges or universities need to optimize the internal management system, especially for the personnel assessment and university-enterprise cooperation mode. The mechanism of rewards and personnel appraisal should be improved and scientific and technological innovation should be strengthened.

Improve both the undergraduates and graduates education. Professional senior undergraduates and graduates' education are one of the most important aspects of the Industry-University-Research cooperation innovation. To improve the quality of graduate education, the first and an urgent task is to build a characteristic graduate and undergraduate course system in collaborative innovation mechanism of colleges, and to strengthen the construction of disciplines. The second is to open some advanced courses to support the students' scientific research. The third is hiring local entrepreneurs as tutors for senior undergraduates and graduates. The forth is making full use of the platform of the graduate workstation, design the collaborative practice in the form of team cooperation for graduates to improve the ability of analyze and solve problems. Moreover, it is important to provide more opportunities for graduates and outstanding senior undergraduates to participate in the enterprise management and science research. So that knowledge of the theory which they learned can be verified and perfected in time, which can enhance the application of innovation capability.

\section{Conclusions}

The Industry-University-Research cooperation innovation of colleges has the powerful effects in promoting the national science and technology innovation. It is speeding up the economic 
development, strengthening the talent cultivation, and it plays an important role in the strategy of invigorating China through science, technology and education. However, there are still various kinds of problems between the university and the local enterprise, such as different results of ownership and intellectual property rights, lack of reasonable risk and profit allocation mechanism, low transformation rate, mismatching between students developments and enterprise requirements. To some extent, these problems restrict the independent innovation of college. Therefore, in the process of collaborative innovation with local enterprises, university or college must be positive to think and explore new methods, strengthen the innovation on scientific research institutions and talent training. At the same time, they also should promote integration of education, science, technology, and economy. And they elevate university personnel training quality and scientific research ability to ascend simultaneously. It needs to strengthen the power of running, improve teaching efficiency and influence. And then the universities or colleges provide better serve to meet the social demand, make efforts to build a world-class and high-level university or college.

\section{Acknowledgements}

This work was financially supported by the Top-notch Academic Programs Project of Jiangsu Higher Education Institutions (TAPP), and funded by teaching reform of Jiangsu University(2015JGYB001).

\section{References}

[1] J.A. Schumpeter: Theory of economic development(Harvard University Press, 1934)

[2] H. Martin, Bstieler L.D., and O. Hiroyuki: Technovation Vol. 34(2014),p. 605

[3] K. J. Leea, T. Ohtab, and K. Kakehib: Technol. Anal. strateg Vol 22(2010), p.189

[4] L. Leydesdorff, and I. Rafols: J. Am. Soc. Inf. Sci. Tec. Vol 62 (2011), p.846

[5] B. Tina, P. Ian, and G. Anne : Eur. Manage. J. Vol 20(2002),p.272 